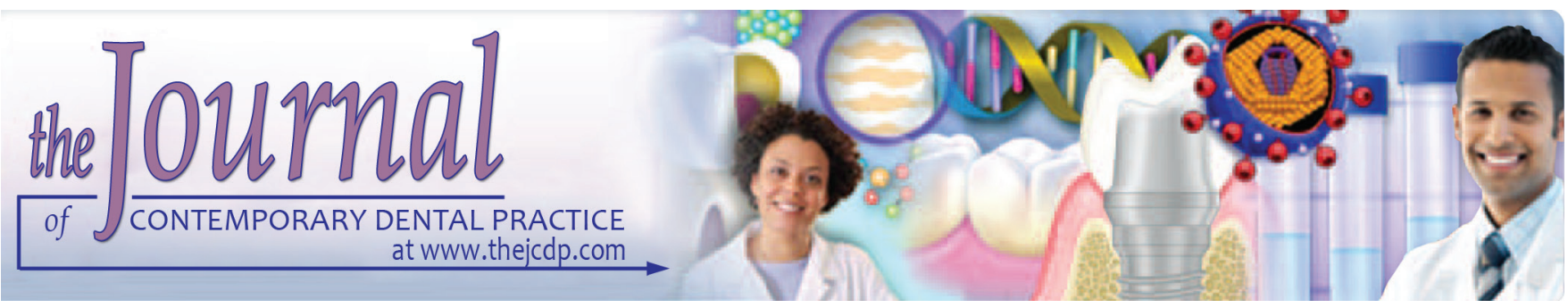

\title{
Estimation of Plasma Levels of Tumor Necrosis Factor- $\alpha$, Interleukin-4 and 6 in Patients with Chronic Periodontitis and Type II Diabetes Mellitus
}

${ }^{1}$ Dipanshu Bakshi, ${ }^{2}$ Guneet Kaur, ${ }^{3}$ Deepinder Singh, ${ }^{4}$ Jasjit Sahota, ${ }^{5}$ Ambika Thakur, ${ }^{6}$ Shekhar Grover

\begin{abstract}
Introduction: Both periodontitis and type II diabetes mellitus (T2DM) are common diseases with a multifactorial etiology and have influence of cytokines in their pathogenesis and thus may also influence each other. In recent times, more attention has been given to understanding the influences of these inflammatory cytokines which are a main part of oral chronic inflammation on systemic health of the individuals. Therefore, the aim of this study was to evaluate the plasma cytokine levels, specifically tumor necrosis factor- $\alpha$ (TNF- $\alpha$ ), interleukin (IL)-6, and IL-4, in chronic periodontitis patients and T2DM patients, so as to investigate the influence of chronic periodontitis in systemic inflammation associated with diabetes mellitus.
\end{abstract}

Materials and methods: The present study comprised a total sample size of 60 patients. A detailed history along with complete periodontal examination were done for each person. These patients were subdivided into four study groups with 15 subjects ( $n=15$ ) in each group: group I: healthy individuals, group II: chronic periodontitis, group III: diabetes mellitus without chronic periodontitis, and group IV: diabetes mellitus with chronic periodontitis. Venous blood was withdrawn for obtaining serum samples from the subjects. Hemoglobin A1c $(\mathrm{HbA} 1 \mathrm{c})$ levels were measured from the automated chromatography. Using enzyme-linked immunosorbent assay kit, TNF- $\alpha$, IL-4, and IL-6 were measured.

\footnotetext{
${ }^{1,5}$ Department of Dentistry, Chintpurni Medical College \& Hospital, Pathankot, Punjab, India

${ }^{2}$ Private Practitioner, Department of Periodontology, Ludhiana Punjab, India

${ }^{3}$ Private Practitioner, Department of Oral and Maxillofacial Surgery, Ludhiana, Punjab, India

${ }^{4}$ Department of Periodontics, Institute of Dental Sciences Jammu, Jammu and Kashmir, India

${ }^{6}$ Department of Public Health Dentistry, Maulana Azad Institute of Dental Sciences, New Delhi, India

Corresponding Author: Shekhar Grover, Department of Public Health Dentistry, Maulana Azad Institute of Dental Sciences, New Delhi, India, Phone: +919501544877, e-mail: drshekhargrover@ yahoo.co.in
}

Results: It was observed that the difference between almost all the results showed statistical significance. Not much of a difference was seen when TNF- $\alpha$ and IL- 6 findings of group II were compared with group III. Furthermore, IL-4 also did not differ when group II was compared with group IV.

Conclusion: The inflammatory cytokines together control the inflammation process and a balance is maintained. However, in patients with diabetes mellitus, this balance is interrupted, which affects the final development and progression of the disease. Thus, hyperglycemia may be partly associated with the severity of the periodontal status in diabetic patients.

Clinical significance: Hyperglycemia thus may play a role in increasing the severity of the periodontal status in diabetic patients. Keeping such relationship in mind, better treatment modalities can be provided to the patients.

Keywords: Chronic periodontitis, Interleukins, Type II diabetes mellitus.

How to cite this article: Bakshi D, Kaur G, Singh D, Sahota J, Thakur A, Grover S. Estimation of Plasma Levels of Tumor Necrosis Factor- $\alpha$, Interleukin-4 and 6 in Patients with Chronic Periodontitis and Type II Diabetes Mellitus. J Contemp Dent Pract 2018;19(2):166-169.

Source of support: Nil

Conflict of interest: None

\section{INTRODUCTION}

Periodontitis is a chronic inflammatory disease of supporting tissues of teeth caused by specific microorganisms or groups of specific microorganisms, resulting in progressive destruction of the periodontal ligament and alveolar bone mediated by proinflammatory mediators. ${ }^{1}$ Periodontal pathogens alter the host immunity-related responses against the bacterial antigens and stimulate specific cytokines. $^{2}$

Type II diabetes is said to be a multifactorial disease, with lowered insulin sensitivity. The prevalence of T2DM 
is growing rapidly worldwide. Patients with T2DM have greater incidence and severity of periodontal diseases than those without diabetes. The National Health and Nutrition Examination Survey data also validates that poor glycemic control in diabetic patients is associated with severity of periodontitis. Various proinflammatory cytokines like TNF- $\alpha$, produced from adipose tissues in obese subjects, are known to play a predominant role in inducing insulin resistance. ${ }^{3,4}$ Both periodontitis and T2DM have influence of cytokines in their pathogenesis and thus may also influence each other. ${ }^{5,6}$

Cytokines are the proinflammatory proteins, discharged by cells and specifically affect the cell-to-cell interactions. They are produced by activated macrophages and are associated with the upregulation of inflammatory reactions. The TNF- $\alpha$ (cachexin or cachectin) is an important proinflammatory mediator that causes destruction of periodontal tissues. It is the most extensively studied cytokine and is active in two forms: TNF- $\alpha$ and TNF- $\beta$. The former is produced by the activated macrophages, neutrophils, keratinocytes, monocytes, and mast cells in response to lipopolysaccharides. It has a role in pathogenesis of both periodontitis and T2DM. ${ }^{7}$

Interleukin 6 may show both destructive or protective functions in chronic disease. ${ }^{8,9}$ Interleukin 4 , another cytokine, is said to decrease the production of both TNF- $\alpha$ and IL-6, and thus may be anti-inflammatory. ${ }^{10}$

In recent times, more attention has been given to understanding the influences of these inflammatory cytokines, which are considered a main part of oral chronic inflammation on systemic health of the individuals. Successful periodontal treatment appears to have beneficial effects on the metabolic control of T2DM.

Therefore, the aim of this study was to evaluate the plasma cytokine levels, specifically TNF- $\alpha$, IL-6, and IL-4, in chronic periodontitis patients and T2DM patients, so as to investigate the influence of chronic periodontitis in systemic inflammation associated with T2DM.

\section{MATERIALS AND METHODS}

The study population in this study comprised a total sample size of 60 patients which were selected from the outpatient department of the institution. A detailed history along with preinformed consent was taken from the patients before including them as subjects in this study. Ethical clearance for this research study was also obtained from the Institutional Ethical Committee. These patients were subdivided into four study groups with 15 subjects $(\mathrm{n}=15)$ in each group:

Group I: Healthy individuals

Group II: Chronic periodontitis

Group III: Diabetes mellitus without chronic periodontitis Group IV: Diabetes mellitus with chronic periodontitis.
The participants of the study aged between 30 and 60 years. Complete periodontal examinations which included plaque index (PI), gingival index (GI), bleeding on probing (BoP), pockets, and clinical attachment loss (CAL) were done for each person using a Williams periodontal probe. Group I subjects had a healthy periodontium with no gingival inflammation $(\mathrm{GI}=0$; pocket depth $\leq 3 \mathrm{~mm}$, and CAL =0). Patients categorized under group II (generalized chronic periodontitis) were those subjects who presented with pocket probing depth (PPD) of $\geq 5 \mathrm{~mm}$ and generalized CAL of $\geq 2 \mathrm{~mm}$ supported by bone loss on radiographs as well. Groups III and IV included subjects who were diagnosed with T2DM from at least past 6 months. Exclusion criteria included smokers, pregnant and lactating women, individuals who underwent periodontal treatment within past 3 months, human immunodeficiency virus infected, or subjects on chemotherapy. After the salivary sample collection, PI, GI, periodontal pocket depth, and loss of attachment were measured by using Williams periodontal probe.

Venous blood was withdrawn from the subjects for obtaining serum samples. The HbA1c levels were measured from the automated chromatography; TNF- $\alpha$, IL-4 and - 6 were measured using enzyme-linked immunosorbent assay kit (Krishgen BioSystems, Mumbai, India).

\section{Statistical Analysis}

All the obtained data were recorded and tabulated and then evaluated statistically. Means and standard deviations (SDs) for each group were calculated; $\mathrm{p} \leq 0.05$ was considered as statistically significant. Relationships between the study groups were calculated by nonparametric tests, such as Mann-Whitney U-test and Wilcoxon signed-rank tests. In detection of correlations between different groups, Spearman's rank correlation test was used.

Statistical Package for the Social Sciences version 21 (SPSS Inc., Chicago, Illinois, USA) was used for statistical analysis.

\section{RESULTS}

In this study, a total of 60 individuals were included, with both male and females almost equally divided. The clinical characteristics recorded for the study population are tabulated in Table 1. For the clinical periodontal

Table 1: Clinical characteristics recorded for the study population

\begin{tabular}{ll}
\hline Variable & Mean $\pm S D$ \\
\hline Age (years) & $51 \pm 8.2$ \\
Gender, $n(\%)$ & \\
Male & $32(53.3)$ \\
Female & $28(46.6)$ \\
Years of diagnosis of diabetes & $8.5 \pm 5.6$ \\
HbA1c $(\%)$ & 7.9 \\
\hline
\end{tabular}


Table 2: Mean clinical periodontal measurements among all the four groups

\begin{tabular}{llllll}
\hline Groups & PI & GI & $P P D$ & CAL & HbA1c (\%) \\
\hline I & $0.25 \pm 0.55$ & $0.27 \pm 0.30$ & - & - & $4.2 \pm 0.55$ \\
II & $1.56 \pm 0.35$ & $1.85 \pm 0.25$ & $7.23 \pm 0.32$ & $6.4 \pm 0.30$ & $5.2 \pm 0.30$ \\
III & $0.30 \pm 0.30$ & $0.36 \pm 0.20$ & $1.3 \pm 0.25$ & $0.9 \pm 0.15$ & $7.1 \pm 0.25$ \\
IV & $2.2 \pm 0.50$ & $2.10 \pm 0.30$ & $6.3 \pm 0.26$ & $6.2 \pm 0.40$ & $7.8 \pm 0.40$ \\
\hline
\end{tabular}

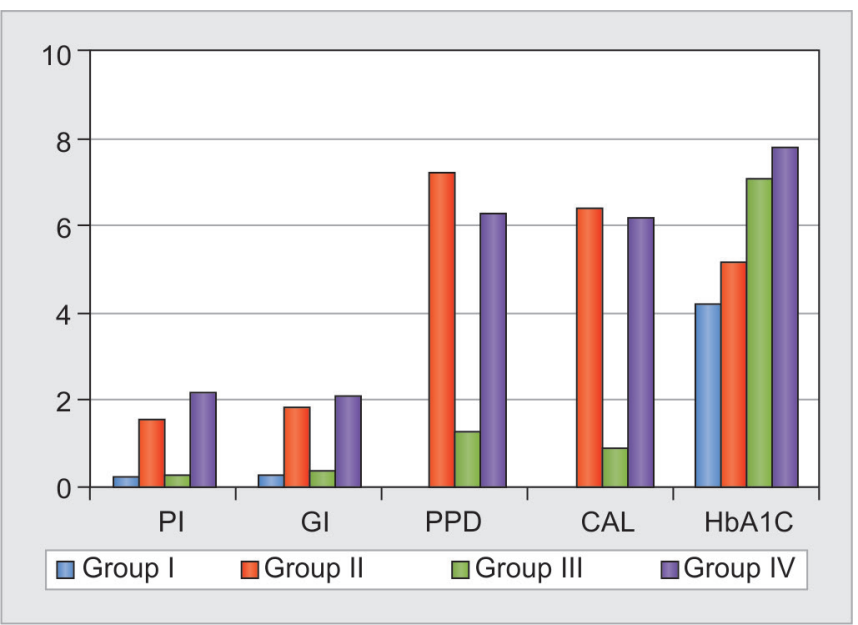

Graph 1: Mean clinical periodontal measurements among all the four groups

Table 3: Means of the serum cytokines TNF- $\alpha$, IL-6, and IL-4 in all the groups

\begin{tabular}{llll}
\hline Groups & $T N F-\alpha$ & IL-6 & IL-4 \\
\hline I & $3.6 \pm 0.25$ & $4.24 \pm 0.40$ & $106.2 \pm 0.25$ \\
II & $15.8 \pm 0.40$ & $22.02 \pm 0.34$ & $30.5 \pm 0.20$ \\
III & $18.4 \pm 0.12$ & $24.2 \pm 0.10$ & $42.11 \pm 0.15$ \\
IV & $27.3 \pm 0.32$ & $39.8 \pm 0.35$ & $25.05 \pm 0.40$ \\
\hline
\end{tabular}

measurements, among all the four groups, the mean values of PI, GI, PPD, CAL, and $\mathrm{HbA} 1 \mathrm{c}$ were calculated and are tabulated in Table 2 and Graph 1. The means of the cytokines of interest in this study (serum TNF- $\alpha$, IL-6, and IL-4) were also recorded for all the four groups and are tabulated in Table 3 and Graph 2.

When intergroup relationships were compared, it was observed that the difference between almost all the results showed statistical significance. Not much of a difference was seen when TNF- $\alpha$ and IL-6 findings of group II were compared with group III. Furthermore, IL-4 also did not differ when group II was compared with group IV. When all the groups collectively were compared, all the cytokines showed a significant correlation with the periodontal clinical parameters observed. No statistically significant correlation was seen except for TNF- $\alpha$ with CAL in group IV and TNF- $\alpha$ with IL-4 in group III.

\section{DISCUSSION}

It is known that T2DM is one of the major risk factors in patients for developing periodontitis and this risk

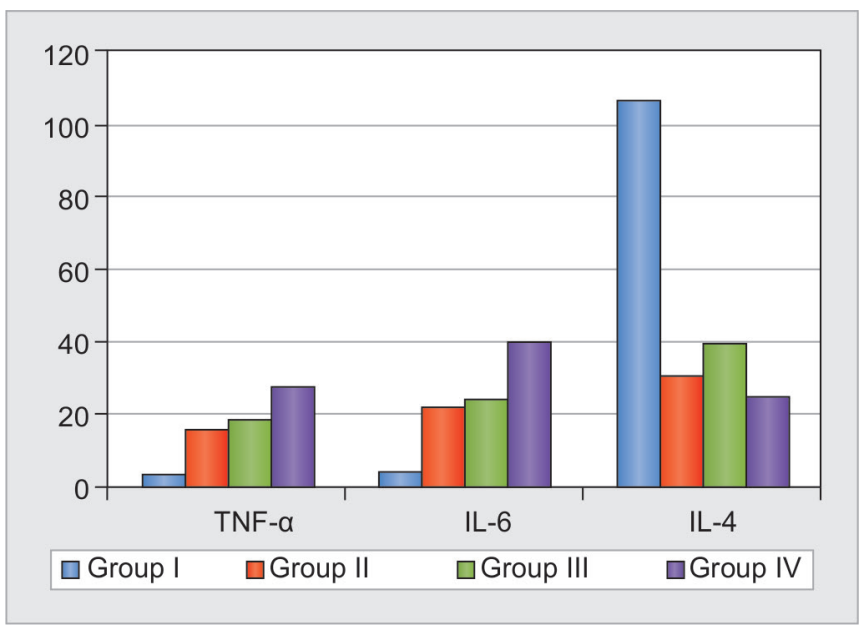

Graph 2: Means of the serum cytokines TNF- $\alpha$, IL-6, and IL-4 in all the groups

is much higher as compared with the healthy subjects. Poorly controlled glycemic status in T2DM subjects not only affects the periodontal status but also is associated with altered immune response, thereby accentuating the inflammatory condition. Thus, a two-way relationship is shared between periodontitis and T2DM. ${ }^{11}$

Although in many earlier studies saliva has been used, being easily available and a noninvasive specimen to detect the various cytokines associated with periodontal diseases, in our study, we used plasma sample because markers, such as TNF- $\alpha$ and IL- 6 are reported to be present in less amount in saliva. ${ }^{12-14}$

In this study, the proportion of male population was higher in comparison to the female population and the male population showed greater duration of uncontrolled diabetes as well.

Further, in the study when clinical parameters, such as GI, PPD, and CAL were compared with the glycemic variable, a significant difference $(\mathrm{p}<0.005)$ was found among these variables between groups II and III and also between groups II and IV. Out of all the studied groups, group IV subjects presented with the highest values for all the periodontal clinical variables and hereby showed a direct positive correlation between the clinical and glycemic parameters. Thus, glycemic control as per our study was found to be related to the severity of periodontitis, which is in accordance with previous studies published. ${ }^{15}$

Among the studied cytokines, TNF- $\alpha$ and IL- 6 presented with elevated levels, while IL-4 did not show such 
results in the diseased groups. Among all the diseased groups, group IV showed the highest values for both TNF- $\alpha$ and IL- 6 and the difference was also clinically significant $(p<0.005)$. These results were in accordance with previous studies out of which one was of Taylor et al. ${ }^{16}$ When intergroup relationships were compared, it was observed that the difference between almost all the results showed statistical significance. Not much of a difference was seen when TNF- $\alpha$ and IL- 6 findings of group II were compared with group III. Furthermore, apart from CAL and TNF- $\alpha$ in group IV, no other clinical variable showed a positive correlation, which is also in accordance with a study done by Saxlin et al, ${ }^{17}$ whereas, on the contrary, lower levels of IL-4 were seen in group IV, and no significant difference was observed between groups II and III, which is in accordance with the results reported by Ribeiro et al. ${ }^{18}$

Thus, our results present elevated TNF- $\alpha$ and IL-6 in diabetic patients, whereas IL- 4 did not show much of an important role in these patients. This is justified by a study done by Taylor et $\mathrm{al}^{16}$ who also quoted that periodontitis is caused by bacterial infection, which initiates the inflammatory process and caused the tissue destruction and attachment loss. In diabetes mellitus, this inflammatory response is modified by elevating the cytokines, especially the IL-6, IL-1 $\beta$, and TNF- $\alpha$, which further progresses the disease and leads to bone destruction by affecting the bone metabolism.

With few limitations, such as less sample size and more detailed history and categorization of the diabetic patients, this study highlights the role of TNF- $\alpha$ and IL-6 in maintenance of periodontal health in diabetic patients.

\section{CONCLUSION}

The inflammatory cytokines together control the inflammation process and a balance is maintained. However, in patients with diabetes mellitus, this balance is interrupted which affects the final development and progression of the disease. Thus, hyperglycemia may be partly associated with the severity of the periodontal status in diabetic patients. Further studies with more sample size should be done to validate this correlation.

\section{Clinical Significance}

Hyperglycemia plays a significant role in increasing the severity of the periodontal status in diabetic patients. Such interrelationships should be kept in mind while providing treatment to the patients.

\section{REFERENCES}

1. Newman MG, Carranza FA, Takei H, Klokkevold PR. Carranzas clinical periodontology. 10th ed. St Louis: Elsevier Health Sciences; 2006.
2. Benakanakere $M$, Kinane DF. Innate cellular responses to the periodontal biofilm. Front Oral Biol 2012;15:41-55.

3. Preshaw PM, Bissett SM. Periodontitis: oral complication of diabetes. Endocrinol Metab Clin North Am 2013 Dec;42(4):849-867.

4. Olszewski MB, Groot AJ, Dastych J, Knol EF. TNF trafficking to human mast cell granules: Mature chain-dependent endocytosis. J Immunol 2007 May;178(9):5701-5709.

5. Thunell DH, Tymkiw KD, Johnson GK, Joly S, Burnell KK, Cavanaugh JE, Brogden KA, Guthmiller JM. A multiplex immunoassay demonstrates reductions in gingival crevicular fluid cytokines following initial periodontal therapy. J Periodontal Res 2010 Feb;45(1):148-152.

6. Iacopino AM. Periodontitis and diabetes interrelationships: role of inflammation. Ann Periodontol 2001 Dec;6(1):125-137.

7. Graves DT, Cochran D. The contribution of interleukin-1 and tumor necrosis factor to periodontal tissue destruction. J Periodontol 2003 Mar;74(3):391-401.

8. Akira S, Taga T, Kishimoto T. Interleukin-6 in biology and medicine. Adv Immunol 1993;54:1-78.

9. Mohamed-Ali V, Goodrick S, Rawesh A, Katz DR, Miles JM, Yudkin JS, Klein S, Coppack SW. Subcutaneous adipose tissue releases interleukin-6, but not tumor necrosis factor-alpha, in vivo. J Clin Endocrinol Metab 1997 Dec;82(12):4196-4200.

10. Tsai CC, Ku CH, Ho YP, Ho KY, Wu YM, Hung CC. Changes in gingival crevicular fluid interleukin-4 and interferon-gamma in patients with chronic periodontitis before and after periodontal initial therapy. Kaohsiung J Med Sci 2007 Jan;23(1):1-7.

11. Preshaw PM, Alba AL, Herrera D, Jepsen S, Konstantinidis A, Makrilakis K, Taylor R. Periodontitis and diabetes: a two-way relationship. Diabetologia 2012 Jan;55(1):21-31.

12. Gursoy UK, Könönen E, Uitto VJ, Pussinen PJ, Hyvärinen K, Suominen-Taipale L, Knuuttila M. Salivary interleukin-1beta concentration and the presence of multiple pathogens in periodontitis. J Clin Periodontol 2009;36:922-927.

13. Gursoy UK, Könönen E, Pradhan-Palikhe P, Tervahartiala T, Pussinen PJ, Suominen-Taipale L, Sorsa T. Salivary MMP-8, TIMP-1, and ICTP as markers of advanced periodontitis. J Clin Periodontol 2010 Jun;37(6):487-493.

14. Gursoy UK, Könönen E, Huumonen S, Tervahartiala T, Pussinen PJ, Suominen AL, Sorsa T. Salivary type I collagen degradation end-products and related matrix in periodontitis. J Clin Periodontol 2013 Jan;40(1):18-25.

15. Acharya AB, Thakur S, Muddapur MV, Kulkarni RD. Tumor necrosis factor- $\alpha$, interleukin- 4 and- 6 in the serum of health, chronic periodontitis, and type 2 diabetes mellitus. J Indian Soc Periodontol 2016;20(5):509-513.

16. Taylor JJ, Preshaw PM, Lalla E. A review of the evidence for pathogenic mechanisms that may link periodontitis and diabetes. J Clin Periodontol 2013 Apr;40 (Suppl 14):S113-S134.

17. Saxlin T, Suominen-Taipale L, Leiviskä J, Jula A, Knuuttila M, Ylöstalo P. Role of serum cytokines tumour necrosis factoralpha and interleukin- 6 in the association between body weight and periodontal infection. J Clin Periodontol 2009 Feb;36(2):100-105.

18. Ribeiro FV, de Mendonça AC, Santos VR, Bastos MF, Figueiredo LC, Duarte PM. Cytokines and bone-related factors in systemically healthy patients with chronic periodontitis and patients with type 2 diabetes and chronic periodontitis. J Periodontol 2011 Aug;82(8):1187-1196. 